\title{
PRESENTE DO SUBJUNTIVO E PRESENTE DO INDICATIVO: UM ENCONTRO NA HISTÓRIA ${ }^{1}$
}

\author{
PRESENT SUBJUNCTIVE AND PRESENT INDICATIVE: \\ A MEETING IN HISTORY
}

Tatiana Schwochow Pimpão

Doutoranda do Programa de Pós-graduação de Linguística - UFSC

\begin{abstract}
Resumo
Resultados da análise de dados sincrônicos (PIMPÃO, 1999b) apontam o traço de futuridade como contexto propício ao uso do presente do modo subjuntivo. Nesse sentido, o objetivo é buscar, mediante consulta em gramáticas históricas, possíveis explicações para o favorecimento do presente do subjuntivo em contextos linguísticos em que o evento codificado na cláusula do dado é projetado para o futuro, i.e., corresponde ao tempo posterior ao momento de fala.
\end{abstract}

Palavras-chave: Variação. Presente do modo subjuntivo. Modalidade deôntica.

\begin{abstract}
The results of our synchronic analysis (PIMPÃO, 1999b) indicate futurity as a favorable context of use of the present subjunctive. In this way, the aim of this paper is to seek, by means of research on historical grammars, possible explanations for the preference of the present subjunctive in linguistic contexts in which the event codified in the clause of the token is projected to the future, i.e., to a moment after the moment of speech.
\end{abstract}

Keywords: Variation. Present subjunctive. Deontic modality.

\section{INTRODUÇÃO}

A variação entre o uso do modo subjuntivo e do modo indicativo tem sido tema de interesse de estudiosos como Poplack (1992; 1994) e Silva-Corvalán (1994): a primeira pesquisa a variação no francês falado no Canadá; já a segunda estudou o espanhol da cidade de Los Angeles. O estudo do uso variável desses modos verbais também tem rendido dissertações de mestrado e teses de doutorado no Brasil. Dentre essas pesquisas menciono algumas: Pimpão (1999b), com a variação entre o presente do modo subjuntivo e o presente do modo indicativo em dados de fala de informantes de Florianópolis/SC (VARSUL) ${ }^{2}$; Neta (2000), com a variação entre formas do presente do indicativo por formas do presente do subjuntivo, a partir de dados (oral e escrito) da cidade de Januária/MG; Meira (2006), que analisa a variação de todos os tempos verbais do modo subjuntivo com o modo indicativo em quatro comunidades afro-brasileiras da Bahia; Carvalho (2007), estudando a alternância entre formas do indicativo e do subjuntivo dos tempos presente e imperfeito com dados do Cariri/CE; Fagundes (2007),

\footnotetext{
${ }^{1}$ Este trabalho foi, primeiramente, apresentado no Rosae, I Congresso Internacional de Linguística Histórica, realizado em Salvador, no período de 26 a 29 de julho de 2009.

${ }^{2}$ Variação Linguística Urbana do Sul do Brasil.
} 
apresentando resultados de variação para todos os tempos do subjuntivo nas quatro cidades do Paraná que integram o Projeto VARSUL.

O estudo desse fenômeno variável sob a ótica diacrônica, entretanto, ainda constitui um campo de trabalho a ser desbravado. Eis a relevância da presente pesquisa: recuar alguns séculos, mais especificamente aos séculos XVI e XIX, buscando, em gramáticas históricas, indícios que possam respaldar resultados sincrônicos que revelam a modalidade deôntica como o contexto propício ao uso do presente do modo subjuntivo (PIMPÃO, 1999b). Para o século XVI será analisada a gramática de João de Barros (1957 [1540]), e, para o século XIX, a gramática de Jeronimo Soares Barboza (1830).

\section{SUBJUNTIVO E A MODALIDADE DEÔNTICA}

A seguir, o modo subjuntivo será focado, segundo duas abordagens: a prescrição normativa e duas perspectivas funcionalistas.

\subsection{As gramáticas tradicionais}

Muitas gramáticas tradicionais estão em consonância ao prescreverem o emprego do modo subjuntivo para situações em que há um grau de incerteza acerca da realização de um determinado evento. Ou seja, as gramáticas normativas costumam associar o modo subjuntivo à modalidade epistêmica ${ }^{3}$, aquela que diz respeito a valores como probabilidade e crença - atuando no eixo do conhecimento (julgamento epistêmico do falante).

Vejamos, então, definições para o modo subjuntivo encontradas em algumas gramáticas tradicionais:

(i) "Emprega-se o subjuntivo em orações dependentes de outras quando o seu fato verbal não é positivo, mas encerra desejo, súplica, incerteza, dúvida” (BUENO, 1963, p. 316);

(ii) "O modo subjuntivo é próprio das orações principais optativas e das subordinadas em que se considera o fato como incerto e duvidoso” (SAID ALI, 1964, p. 166);

(iii) “O SUBJUNTIVO, expressão de um desejo, apresenta o fato como possível ou duvidoso” (CUNHA, 1978, p. 255);

(iv) "Subjuntivo - em referência a fatos duvidosos, prováveis, possíveis" (BECHARA, 1980, p. 104);

(v) “'Modo da possibilidade’. Usa-se para exprimir um fato possível, incerto, hipotético, irreal ou dependente de outro” (CEGALLA, 1981, p. 377);

\footnotetext{
${ }^{3}$ É verdade que as gramáticas normativas não empregam a terminologia modalidade epistêmica. Entretanto, considerando que, nessas gramáticas, ao modo subjuntivo são atribuídos, essencialmente, valores de incerteza, pode-se situar o subjuntivo no eixo epistêmico.
} 
(vi) "O modo subjuntivo indica dependência também quando o fato é duvidoso ou indeterminado, sendo por isso chamado "modo da possibilidade"” (MENDES DE ALMEIDA, 1981, p. 226).

Embora a segunda e a terceira definições façam uma menção à modalidade deôntica, observa-se que, de uma maneira geral, as gramáticas vinculam o uso do modo subjuntivo ao mundo da possibilidade, da incerteza,. Nesse sentido, segundo essas gramáticas, o falante, ao empregar esse modo verbal, expressa uma atitude de incerteza em relação ao que fala. Diferente dessa prescrição, Pimpão (1999b) constatou uma forte correlação entre o uso do presente do subjuntivo e a modalidade deôntica, interpretada como tendo certo valor temporal, e não entre o modo subjuntivo e somente o traço de modalidade associado à incerteza. A modalidade deôntica se sobressaiu nesse estudo a partir da seleção recorrente em diferentes rodadas estatísticas de uma variável independente, cujos fatores indicavam se uma determinada ocorrência tinha um traço de futuridade ou não.

Na seção seguinte, essas questões que envolvem a modalidade serão mais bem analisadas, considerando a teoria funcionalista de Givón (1995; 2001) e a proposta de Bybee et al. (1994).

\subsection{A Perspectiva funcionalista: Givón e Bybee et al.}

Givón (1995) parte do pressuposto de que, para compreender o lugar do modo subjuntivo, é necessário, antes, compreender o lugar da modalidade irrealis. Isso porque o irrealis instaura-se no eixo comunicativo, por meio de estratégias linguísticas que propiciam o uso do modo subjuntivo. Nesse tipo de modalidade, uma proposição é fracamente asserida, não sendo possível ao falante fornecer evidências para defender a informação proposicional, seja por essa ser incerta, seja por ser desejada. O desafio da informação, por parte do ouvinte, é, portanto, altamente esperado. Não havendo evidências, a possibilidade de contestação é alta e previsível.

Como a teoria givoniana é de base comunicativa, a noção de modalidade é atravessada pela comunicação. Por essa razão, o falante aproxima-se da informação que veicula, estabelecendo avaliações. Também por isso, Givón (1993, p. 169; 1995, p. 112) atribui à modalidade a propriedade de assinalar a atitude do falante sobre o conteúdo de sua proposição. Essa atitude bifurca-se em julgamentos do falante, ambos denominados, por Givón (1995, p. 112), sub-modos irrealis, conforme a seguir reproduzido: “epistemic attitudes: truth, belief, probability, certainty, evidence. Valuative attitudes: desirability, preference, intent, ability, obligation, manipulation”.

Givón (1993, p. 172; 1995, p. 121) estabelece um traço comum aos sub-modos epistêmico e deôntico da modalidade irrealis, a incerteza epistêmica. A modalidade deôntica implica um traço inerente de futuridade; portanto, também de incerteza epistêmica. A base distintiva entre ambas as modalidades (epistêmica e deôntica) está no traço de futuridade. Conforme Givón (1984, p. 285), "the future is a clear irrealis tense"; além disso, "the future is by definition an irrealis mode” (GIVÓN, 1993, p. 172). 
Considerando a caracterização apresentada por Givón (1993; 1995; 2001) para a modalidade, nota-se que esse traço de futuridade tem relação com valores como desejo, intenção, preferência, obrigação, permissão, manipulação, que são típicos da modalidade deôntica - atuando no eixo da conduta (julgamento avaliativo/deôntico). Daí a correlação assimétrica entre os sub-modos: se deôntico, então incerteza epistêmica (mas não necessariamente vice-versa) (GIVÓN, 1993, p. 172; 1995, p. 122). Isso porque os sentidos deônticos são projeções futuras, portanto carregam incerteza epistêmica. Entretanto, não necessariamente a incerteza epistêmica implica uma projeção futura, podendo haver um julgamento de incerteza a respeito de fatos passados.

Considerando as passagens de Givón (1984; 1993; 1995; 2001), percebemos uma visível relação entre modalidade deôntica, traço de futuridade e modo subjuntivo. Essa tríade sustenta os resultados obtidos no estudo da variação entre o presente do modo subjuntivo e o presente do modo indicativo (PIMPÃO, 1999b). Nesse estudo, a modalidade deôntica, a partir do traço de futuridade, constitui o contexto propício ao uso do subjuntivo, evidenciando que a teoria respalda a interpretação dos resultados quantitativos.

Assim, à medida que o traço de futuridade desaparece e, com ele, a incerteza, diminui, igualmente, o emprego do subjuntivo, e aumenta o uso do presente do modo indicativo. Tem-se, dessa forma, a seguinte correlação entre traços semântico-pragmáticos e o uso do presente no modo subjuntivo versus o uso do presente do modo indicativo.

$$
\begin{aligned}
& {[+ \text { incerteza }][+ \text { futuridade }]=[+ \text { presente do modo subjuntivo }]} \\
& {[+ \text { incerteza }][ \pm \text { futuridade }]=[- \text { presente do modo subjuntivo }]} \\
& {[- \text { incerteza }][- \text { futuridade }]=[- \text { presente do modo subjuntivo }]^{4}}
\end{aligned}
$$

Ainda que a junção de traços seja binária, a associação de dois valores positivos, de um valor positivo e outro negativo, e de somente valores negativos, retrata, com bastante propriedade, o ambiente em que o presente do modo subjuntivo é privilegiado, da mesma forma que reflete o ambiente em que esse emprego é moderadamente desfavorecido e pouco condicionado (PIMPÃO, 1999b).

Um pouco diferente da visão de Givón (1984; 1993; 1995; 2001), mas não opostos a ele, estão Bybee et al. (1994), ao tratarem da modalidade irrealis. Considerando a leitura da área de modalidade e, a partir de estudos em várias línguas do mundo, os autores tomam um caminho um pouco diferente de Givón (op. cit.). Ainda que concordem que a base binária da distinção realis/irrealis não explica a complexidade do fenômeno da modalidade (também explícito na teoria givoniana), acreditam que essa distinção não é válida para todas as línguas, pois línguas diferentes podem apresentar marcas morfológicas para a modalidade realis, ao passo que outras línguas podem categorizá-las como modalidade irrealis.

Para esses autores (1994, p. 177-181), há quatro tipos de modalidade: modalidade orientada para o agente, modalidade orientada para o falante, modalidade epistêmica e

\footnotetext{
${ }^{4} \mathrm{O}$ conjunto de traços tem o objetivo analisar, separadamente, as duas bases para a modalidade deôntica: a incerteza epistêmica e o traço de futuridade (GIVÓN, 1993, p. 172; 1995, p. 122), conforme abordado na página 3 deste artigo. Nesse sentido, a incerteza constitui um traço binário (positivo ou negativo) e a futuridade um continuum, evidenciando uma escala, em que os pólos são a presença e a ausência.
} 
modo subordinante. O primeiro tipo de modalidade indica a existência de condições internas e externas do agente com respeito à realização da ação expressa na cláusula matriz. O segundo tipo, por sua vez, permite imposições de certas condições por parte do falante para o ouvinte. Já o terceiro tipo, modalidade epistêmica, sinaliza o comprometimento do falante com a verdade da proposição. Por fim, para o modo subordinante são usadas as mesmas formas dos dois tipos de modalidade anteriores, mas com a particularidade de serem frequentemente utilizadas sob o escopo de determinadas orações subordinadas.

Bybee et al. (1994, p. 212) tratam muito do modo subjuntivo na quarta modalidade, referente ao modo subordinante. Ao tratarem das quatro modalidades, mencionam que a modalidade orientada para o agente evolui para as modalidades orientada para o falante e epistêmica e ainda como essas últimas podem ser usadas em orações subordinadas (1994, p. 181). Segundo eles (1994, p. 213), há uma controvérsia sobre o uso do modo subjuntivo, pois não há clareza se esse modo verbal carrega significado ou se, semanticamente esvaziado, fica sujeito às exigências sintáticas. Como exemplo, afirmam que, nas línguas em que há esse modo, a maioria dos seus usos não expressa um contraste semântico, porém corresponde a uma exigência do contexto circundante.

Retomando Lyons (1977, p. 807 apud Bybee et al., 1994, p. 214), os autores falam em situações modalmente harmônicas para aquelas em que um verbo modal e um advérbio expressam o mesmo grau de modalidade, sem que o efeito modal seja duplicado pela presença de um segundo termo. E nesse ponto sobre contexto harmônico, os autores ainda assinalam uma importante contribuição de Palmer sobre o modo subjuntivo (1986, p. 132 apud Bybee et al., 1994, p. 218-219): “many cases where the subordinate clause uses a subjunctive reflects its main clause uses”. Ainda sobre esse assunto, é importante a passagem em que os autores mencionam a harmonia entre a modalidade orientada para o agente e o futuro, a partir de complementos de verbos como querer e de orações finais (1994, p. 230).

Essas considerações são relevantes na medida em que sugerem uma relação harmônica no contexto linguístico, permitindo algumas correlações: o uso do subjuntivo harmonicamente relacionado a certos verbos da oração matriz ou a determinadas conjunções introdutoras de orações subordinadas. Ainda, se a harmonia entre a modalidade orientada para o agente e o futuro for estendida para as duas modalidades subsequentes - orientada para o falante e epistêmica - teríamos também o modo subjuntivo.

\subsection{Correlações teóricas}

É oportuno estabelecermos um quadro comparativo entre as propostas de Givón (1984; 1993; 1995; 2001) e de Bybee et al. (1994) para a modalidade.

Os autores concordam com a primazia da modalidade deôntica sobre a modalidade epistêmica; entretanto, há apenas um diferencial: Bybee et al. (1994) consideram, ainda, a existência do modo subordinante, modo esse requerido pelo contexto harmônico e com pouco indício de traduzir modalidade. 
QUADRO 1. Quadro comparativo para modalidade

\begin{tabular}{|cc|}
\hline Bybee et al. (1994) & Givón (1984; 1993; 1995; 2001) \\
\hline modalidade orientada para o agente & modalidade deôntica \\
\hline modalidade orientada para o falante & \\
\hline modalidade epistêmica & modalidade epistêmica \\
\hline modo subordinante & - \\
\hline
\end{tabular}

\section{ANÁLISE DE DADOS}

Os dados ${ }^{5}$, reproduzidos na sequência, foram retirados de Pimpão (1999b), que os submeteu à análise estatística do programa computacional VARBRUL, considerando grpos de fatores linguísticos e sociais. Esses dados ilustram o conjunto de traços apresentado na página 4. Para ilustrar cada um desses conjuntos, discuto algumas ocorrências de variação entre presente do subjuntivo e presente do indicativo.

Antes, porém, julgo pertinente apresentar uma tabela com os resultados da relação tempo-modalidade $^{6}$ e o uso do presente do modo subjuntivo, para demonstrar a associação entre o traço de futuridade e o emprego desse modo verbal, i.e., entre a modalidade deôntica e o modo subjuntivo. Esse traço de futuridade está diretamente ligado à modalidade deôntica, pois esse eixo caracteriza-se pela projeção futura; já o traço de incerteza situa-se no eixo epistêmico, caracterizado pelas crenças do falante (c. seção 2.2).

TABELA1. Correlação entre fatores e uso do presente do subjuntivo (adaptado de PIMPÃO, 1999b) ${ }^{7}$

\begin{tabular}{|lccc|}
\hline \multicolumn{1}{|c}{ Fatores } & Apl./Total & Percentual & P.R. \\
\hline Futuridade & $106 / 128$ & 83 & 0,75 \\
\hline Atemporalidade & $34 / 72$ & 47 & 0,36 \\
\hline Incerteza & $22 / 55$ & 40 & 0,30 \\
\hline Pressuposição & $25 / 64$ & 39 & 0,29 \\
\hline TOTAL & $187 / 319$ & 59 & \\
\hline
\end{tabular}

Na tabela acima, observamos um percentual alto (83\%), associado a um peso relativo também alto $(0,75)$, favorecendo o uso do presente do modo subjuntivo sob o escopo da modalidade deôntica. Vale lembrar que essa modalidade projeta um determinado evento para o futuro, eixo da modalidade irrealis, contexto propício para o modo subjuntivo

\footnotetext{
${ }^{5}$ Os dados de variação entre presente do modo subjuntivo e presente do modo indicativo recobrem cinco tipos de contextos sintáticos: orações substantivas, orações adverbiais, orações relativas, orações com o advérbio talvez e orações com construções negativas, como não (é) que, não (é) porque (PIMPÃO, 1999b).

${ }^{6}$ Tempo-modalidade constitui um dos grupos de fatores controlado por Pimpão (1999b). O controle dessa variável justifica-se pela necessidade de avaliar o uso do modo subjuntivo com a modalidade irrealis. Assim, à medida que o irrealis enfraquece, permitindo uma extensão à modalidade realis, também diminui o uso emprego do subjuntivo. Essa variável apresenta quatro fatores: futuridade (+ incerteza e + futuridade), incerteza e atemporalidade (+ incerteza e \pm futuridade) e pressuposição (- incerteza e futuridade), que serão retomados na análise de dados.

${ }^{7}$ Os resultados apresentados na Tabela 1, embora não constem na dissertação de Pimpão (1999b), provêm das rodadas estatísticas realizadas durante a pesquisa.
} 
(GIVÓN, 1984; 1993; 1995; 2001). Nesse sentido, a diminuição do traço de futuridade desfavorece o subjuntivo: 0,36 (47\%) para atemporalidade (o evento situa-se na fronteira realis-irrealis, não estando, portanto, somente projetado para o futuro) e 0,30 (40\%) para incerteza (julgamento epistêmico do falante). Por fim, a pressuposição, com 0,29 (39\%), embora com peso próximo ao anterior, constitui o fator que mais desfavorece o uso desse modo verbal, isso porque a futuridade não se faz presente, nem a incerteza, i.e., caracteriza-se por um contexto de ausência da modalidade deôntica. Esses resultados revelam que a distância em relação ao contexto de modalidade deôntica desfavorece o uso do subjuntivo. Como os três últimos fatores mostram um comportamento bastante próximo, procedeu-se a um amálgama, conforme ilustra a Tabela 2.

TABELA 2. Associação entre traço de futuridade e uso do presente do subjuntivo (extraído de PIMPÃO, 1999b, p. 73)

\begin{tabular}{|lccc|}
\hline \multicolumn{1}{|c}{ Fatores } & Apl./Total & Percentual & P.R. \\
\hline Futuridade & $106 / 128$ & 83 & 0,76 \\
\hline inc./atemp./pressup. & $81 / 191$ & 42 & 0,31 \\
\hline TOTAL & $187 / 319$ & 59 & \\
\hline
\end{tabular}

Os resultados probabilísticos da Tabela 2 confirmam a correlação entre o modo subjuntivo e os traços positivos para incerteza e futuridade. Assim, eventos, cuja possível realização está projetada para o futuro, situam-se na modalidade irrealis, submodo deôntico, constituindo um contexto favorecedor ao modo subjuntivo.

A partir da análise quantitativa, vamos, agora, analisar as primeiras ocorrências, as que se referem ao conjunto de traços [+ futuridade] e [+ incerteza].

(1) Por exemplo, nós temos uma coisa que são normas. Existe um sinal vermelho pra que você não AVANCE. Ele olha para o lado, não vê ninguém, ele toca. Mas, se tiver um guarda, ele não faz. (FLP 13, L0783) ${ }^{8}$

(2) (est) todo mundo diz que é pra mim mudar que eu sou muito assim é [ai como é]- ai como é que eu posso te dizer, [eu]- eu [não]- [não]- [não]- não queria mudar porque eu sou eu, eu sou os outros, eu não sou o que eles querem que eu SOU, eu não tenho que ser o que eles querem. (FLP 05, L1425)

O primeiro exemplo é de uma oração adverbial introduzida pela conjunção para que, e o segundo de uma oração substantiva, com o verbo querer na oração matriz. A particularidade das orações sob o escopo desses termos é a não exigência de um contexto linguístico maior para que a situação retratada na oração subordinada possa ser percebida como projetada para o futuro. Os próprios termos - para que e querer -, por si sós, já carregam um traço de futuridade inerente. Ainda assim, vamos analisar ambas as ocorrências.

\footnotetext{
${ }^{8}$ As entrevistas analisadas estão armazenadas no Bando de Dados do Projeto VARSUL, sendo cada informante codificado da seguinte forma: as letras iniciais entre parênteses, ao final de cada dado, indicam a cidade (Florianópolis), o número seguinte identifica a entrevista e os números finais sinalizam a linha em que o dado pode ser encontrado.
} 
Conforme o primeiro dado, a existência de um sinal vermelho na sinaleira não garante que o condutor de um determinado veículo vá respeitar o significado da cor e aguardar a mudança para o sinal verde. De acordo com a lei de trânsito, o sinal vermelho deveria coibir o desejo de seguir com o veículo, entretanto avançar ou não esse sinal é uma ação dependente da decisão do motorista, portanto futura em relação à própria permanência da cor vermelha.

O segundo dado retrata uma situação familiar. A informante, ao relatar sobre seu comportamento, menciona que alguns de seus familiares desejam que ela mude. Entretanto, ela manifesta seu desejo de ser como é e não como as demais pessoas gostariam. Assim, ao usar o verbo querer, que expressa a vontade de seus familiares, a oração que está sob o escopo desse verbo é, automaticamente, projetada para o futuro. A projeção futura é uma característica dos verbos volitivos, como o da ocorrência (2), verbos esses que lançam o alvo do desejo para o futuro. Nesse sentido, a realização do alvo do desejo pode ocorrer ou não. Como a realização do objeto do querer projeta-se para o futuro, há uma confluência entre o traço deôntico de futuridade e a incerteza epistêmica.

A análise desses dois trechos ilustra a associação de traços positivos [+ incerteza] e [+ futuridade]. Na verdade, como já mencionado, o traço de futuridade implica a incerteza, pois o futuro é incerto, e essa relação de traços positivos constitui um contexto fortemente propício ao uso do presente do modo subjuntivo.

Os traços positivos foram encontrados em dois tipos de contextos linguísticos: i) o traço de futuridade, portanto de incerteza (modalidade deôntica) constitui uma propriedade intrínseca de alguns itens lexicais (verbo deôntico, conector de oração final e conector de oração temporal); ii) o traço de futuridade é identificado contextualmente (verbo epistêmico, oração relativa e advérbio talvez, quando acompanhados, por exemplo, do verbo ir (indicação de movimento), da conjunção se (hipótese) e de modais (ter que, por exemplo)). A seguir, apresento algumas ocorrências.

(3) Eu se eu chegar a me aposentar, talvez SEJA pela idade, né? (FLP 07, L0558)

(4) A FUCABEM só recolhe o menor quando ele já está perdido, quer dizer, então aí não adianta mais recolher. Então nós temos que ter uma casa de abrigados, mas que PEGUE a criança ou o garoto, antes de ele cair no mal. (FLP 02, L0821)

Observa-se, nas ocorrências acima, um enunciado com o advérbio talvez e um enunciado de oração relativa, estando a futuridade diluída no contexto linguístico, i.e., o traço de futuridade é identificado em outras estratégias, como o condicional se (3) e o modal temos que (4).

As próximas ocorrências referem-se ao conjunto de traços [+ incerteza] [ \pm futuridade]. Em Pimpão (1999b, p. 71-73), esses traços dizem respeito a ocorrências em que há incerteza, bem como a ocorrências em que se verifica uma atemporalidade, semelhante ao que alguns autores denominam habitualidade (GIVÓN, 1995; 2001). Passemos à análise das ocorrências. 
(5) Mas eu acredito_que HÁ uma força superior, né? (est) Hã, deixa eu ver, a igreja assim, ela proíbe demais, ela devia ser um pouquinho mais liberal, as missas deveriam ter corais. (FLP 17, L1080)

(6) É, realmente é super gostoso. Talvez porque a gente se QUEIRA tanto que a gente, [na]- na época que vem a morte, né? a gente não aceita, tu entendes? (FLP 11, L0360)

Os dois dados acima, (5) e (6), com o verbo acreditar e com o advérbio talvez, respectivamente, estão inseridos em orações que traduzem incerteza, mas não futuridade, pois o evento codificado na oração subordinada não é projetado para o futuro. Em (5), a crença é fracamente asseverada; a informante acredita na existência de uma força superior, mas não fornece pistas que confirmem sua crença. Em (6), muito semelhante é a análise, pois a situação retratada também é de incerteza: há uma dúvida sobre a dificuldade de aceitar a morte. Estaria essa dificuldade ligada ao amor, à amizade existente entre os membros da família? Segundo o informante, parece que é, mas não há certeza.

Nesses dois dados, a combinação de um traço positivo, incerteza, e de um traço negativo, futuridade, constitui um cenário para uma diminuição do emprego do modo subjuntivo, promovendo, assim, o presente do modo indicativo. Pimpão (1999b, p. 71) cita itens lexicais - verbos epistêmicos e o advérbio talvez -, que carregam a noção de incerteza, sem que a presença do traço de futuridade seja identificada no contexto linguístico, como ambientes favorecedores ao uso do subjuntivo.

Ainda correspondem aos traços [+ incerteza] [ \pm futuridade] ocorrências que retratam um “evento habitual, seja por apresentar uma hipótese, uma condição, acerca de um evento conhecido pelo falante” (PIMPÃO, 1999b, p. 72). Por essa propriedade particular de codificarem um evento que costuma se realizar, essas ocorrências foram denominadas atemporais, por espraiarem-se entre passado, presente e futuro. São exemplos de atemporalidade enunciados com orações relativas, alguns conectores adverbiais concessivos (mesmo que, nem que) e conectores condicionais (desde que), sem que haja um traço de futuridade e desde que se perceba, pelo texto produzido pelo informante, que o evento-dado é conhecido.

Vejamos alguns trechos de entrevistas para análise.

(7) Não gosto de ir ao cinema, teatro. Teatro assim quando é uma peça que te CHAMA atenção, que tu vês que está, né? fazendo propaganda, né? Aí eu gosto. (FLP 04, L0465)

(8) A gente botou venda e, geralmente quem tem venda, mesmo que não TENHA lucro, mas o dono da venda, né? os filhos, não passam tão mal. (FLP 12, L0795)

(9) Da Farra-do-Boi? Não tenho nada contra, desde que não MATE o boi, não FIRA o boi. (FLP 15, L0585) 
Nas ocorrências acima, percebemos que o evento da oração subordinada parece ser de conhecimento do informante. Em (7), o informante, embora não goste de teatro, sugere que frequenta esse espaço quando a peça chama sua atenção. Em (8), a informação de quem tem venda não passa tão mal indica que, ou o informante já passou por situação semelhante, ou conhece alguém que já a experienciou. Por fim, em (9), o informante fala sobre a Farra do Boi, parte da cultura popular do estado de Santa Catarina, especificamente no litoral, prática essa provavelmente de origem portuguesa. Como é de conhecimento geral, a Farra do Boi leva muitos animais à morte. Ainda que o informante não participe dessa tradição popular, tem conhecimento sobre o massacre dos animais.

A seguir, as ocorrências que apresentam ausência de traços: [- incerteza] e [futuridade]. Apresentarei ocorrências com a negação (não é que), mas também se enquadram nessa ausência de traços alguns conectores concessivos (embora, se bem que e apesar de que) e as expressões intercaladas com que.

(10) Bom, eu acho que o Plano do Presidente Collor ele é - No global, ele é um plano bom, embora eu não ENTENDA de economia e não teria, assim, condições de fazer uma análise mais profunda do que é o Plano. Mas entendo realmente que ele deu o tiro certo. (FLP 21, L0427)

(11) ENT.: Ah, ah, a senhora gosta de política, então?

Não é que eu GOSTO de política, eu gosto, assim, de ver como é que está a política, né? essas coisas aí que a gente está escutando todo dia, aí. (FLP 15, L0135)

(12) Ah, mas, assim, o que mais me marcou, que eu me LEMBRO, foi isso, que foi muito engraçado. Da árvore, né? da árvore que a gente se jogava de uma pra outra e de King Kong que era muito engraçado. (FLP 01, L0131)

Ocorrências como (10-12) mostram que a ausência de traços desfavorece o subjuntivo, permitindo o aparecimento do presente do indicativo. Em (10), o informante fala sobre o Plano Collor, afirmando ser esse um plano bom. Essa informação poderia desencadear, no entrevistador, a inferência de que o entrevistado entende de economia. Assim, o informante atribui essa inferência ao ouvinte/entrevistador e, antes mesmo que esse a mencione, se é que a mencionaria, cancela a inferência, afirmando embora eu não entenda de economia.

Aproximando-se da análise anterior, o dado (11) também se caracteriza pelo cancelamento de inferência, entretanto há um diferencial: a inferência não é pressuposta, mas manifesta. Embora não haja um contexto linguístico, a pergunta do entrevistador pressupõe que o informante tenha mencionado algo que suscitou a inferência: Ah, ah, a senhora gosta de política, então? Ao ouvir essa constatação e por não concordar com ela, o informante cancela essa inferência, afirmando: Não é que eu gosto de política... (cf. PIMPÃO, 1999a).

A última ocorrência, (12), assemelha-se à 10, pois o informante, ao falar sobre qual acontecimento da infância mais o marcou, menciona duas situações: a brincadeira na árvore e de King Kong. Para que o entrevistador não pense que de fato foram esses dois 
acontecimentos mais marcantes, o informante faz uma ressalva ao dizer que eu me lembro. Essa construção tem a propriedade de cancelar uma possível inferência por parte do ouvinte e, antes que esse a manifeste, o falante já a cancela.

Essas ocorrências ilustram duas possibilidades: ou o informante atribui uma inferência ao entrevistador e a cancela, ou o informante cancela a inferência, após o entrevistador manifestá-la. De qualquer forma, nos três casos, a oração em que aparece o dado relevante não revela uma situação/um evento incerto e/ou futuro: o informante não entender de economia, o informante não gostar de política e o informante mencionar dois acontecimentos de que se lembra.

\section{GRAMÁTICAS HISTÓRICAS}

Para esta pesquisa inicial, serão analisadas apenas duas gramáticas: a de João de Barros (1957 [1540]) e a de Jeronimo Soares Barboza (1830) ${ }^{9}$. Barros (1957 [1540], p. 29) apresenta cinco modos verbais: indicativo, imperativo, outativo, subjuntivo e infinitivo. Por sua vez, Barboza (1830, p. 200-201) elenca três modos verbais: o infinito (o mesmo infinitivo), o indicativo (que inclui o imperativo e o suppositivo) e o subjuntivo (que reúne os modos outativo e subjuntivo listados por Barros (op. cit.)).

\subsection{Gramática de João de Barros}

A análise de algumas morfologias flexionais dos modos outativo e subjuntivo em Barros (1957 [1540], p. 31-33) é de suma importância para o fenômeno variável em estudo. Com relação ao tempo-modo, a morfologia do presente do modo indicativo da época da gramática é idêntica à morfologia que observamos em nossas gramáticas atuais.

$\begin{array}{cc}\text { Tempo presente } & \underline{\text { Plural }} \\ \text { Amo - amas - ama } & \text { Amamos - amais - amam } \\ \text { Leio - lês - lê } & \text { Lemos - ledes - lêm } \\ \text { Ouço - ouves - ouve } & \text { Ouvimos - ouvis - ouvem } \\ \text { Sou - és - é } & \text { Somos - sois - são }\end{array}$

Entretanto, a informação interessante está na seção em que o gramático trata dos modos verbais outativo e subjuntivo. Neste momento, vale relembrar que o modo subjuntivo de hoje estava diluído em dois modos verbais: o outativo (modo para desejar) e o subjuntivo (modo para ajuntar).

Vejamos, a seguir, em que tempo verbal do modo outativo Barros (1957 [1540], p. 3233) inclui a morfologia flexional do presente do modo subjuntivo que conhecemos atualmente. Para tanto, reproduzirei a flexão verbal de tempo-modo descrita por esse gramático para o presente e para o futuro do modo outativo.

\footnotetext{
${ }^{9}$ Embora haja uma lacuna temporal entre ambas as gramáticas, a escolha justifica-se por duas razões: (i) disponibilidade de material e (ii) relevância das informações encontradas nessas gramáticas para o estudo da relação entre o uso do presente do modo subjuntivo e a modalidade deôntica.
} 


\author{
Tempo presente \\ Singular \\ Amasse - amasses - amasse \\ Plural \\ Amássemos - amásseis - amassem

\section{Tempo vindouro} \\ $\underline{\text { Singular }}$ \\ Ame-ames - ame \\ Amemos - ameis - amem
}

Observamos que a morfologia verbal para o presente do modo subjuntivo que hoje verificamos nas gramáticas tradicionais estava relacionada ao futuro, denominado tempo vindouro, segundo Barros (1957 [1540], p. 33). Essa informação é extremamente relevante para a busca de uma correlação histórica entre o emprego do modo subjuntivo atual e a modalidade deôntica (associação de incerteza e um traço de futuridade). $\mathrm{O}$ modo outativo é o modo do desejo; sendo assim, o objeto do desejo é sempre projetado ao futuro. Nesses termos, a morfologia de presente do subjuntivo que hoje temos codificava eventos futuros, conforme a gramática de Barros (1957 [1540], p. 32-33).

Vejamos, agora, a morfologia verbal do presente e do futuro do modo subjuntivo (modo de ajuntar) em Barros (1957 [1540], p. 34). De acordo com o referido gramático, o nosso presente do modo subjuntivo igualmente é classificado como presente, conforme esquema abaixo reproduzido.

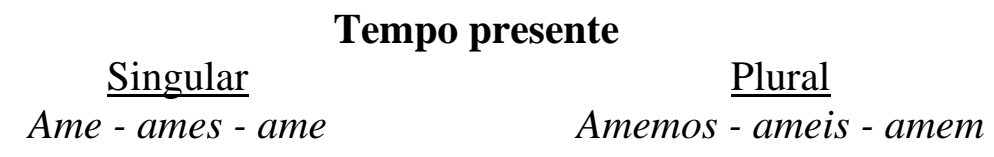

Tempo vindouro
Amar - amares - amar $\quad$ Amarmos $-\frac{\text { Plural }}{\text { amardes - amarem }}$

Essas correlações temporais e modais observadas na gramática histórica de Barros (1957 [1540]) são valiosas, pois delas podemos destacar algumas reflexões:

(i) de fato, parece plausível sustentar a correlação entre o uso do presente do modo subjuntivo e a modalidade deôntica, conforme resultado da análise de dados sincrônicos estudados por Pimpão (1999b). A morfologia que hoje identifica o presente do modo subjuntivo era sinalizada pela mesma morfologia atual, mas em outra correlação tempo-modo: tempo vindouro do modo outativo ${ }^{10}$. Segundo Barros (1957 [1540], p. 29) esse é o modo do desejo. Esse encontro na história, a saber, tempo vindouro, modo outativo/do desejo e morfologia do que temos hoje como presente do subjuntivo, fornece uma explicação para a preservação do nosso presente do modo subjuntivo atual em contextos de modalidade deôntica;

\footnotetext{
${ }^{10}$ Novamente, vale destacar que o modo subjuntivo atual abarca os modos verbais outativo e subjuntivo descritos por Barros (1957 [1540]), mas o contrário não é verdadeiro, i.e., o modo outativo é apenas parte do que conhecemos atualmente como modo subjuntivo.
} 
(ii) o presente do modo subjuntivo atual é equivalente ao presente do modo subjuntivo em Barros (1957 [1540], p. 34), diferentemente do modo outativo em que essa mesma morfologia aparece no tempo vindouro. Essa equivalência poderia indicar uma extensão do uso da morfologia do presente do subjuntivo atual do tempo vindouro do modo outativo para o tempo presente do modo subjuntivo, ambos os últimos descritos por Barros (1957 [1540], p. 32-33). Assim, a expansão da morfologia para outros tempos, como do vindouro para o presente, contribuiria para afrouxar a relação do subjuntivo com a modalidade deôntica, permitindo o aparecimento de outra morfologia, a do presente do modo indicativo.

Essas duas reflexões têm o caráter de hipóteses; ainda que assentadas em bases seguras, precisam ser verificadas, seja com a análise de um maior número de dados, seja com a análise de outras gramáticas históricas. Certo é que tais informações são preciosas, merecendo uma averiguação mais acurada.

\subsection{Gramática de Jeronimo Soares Barboza}

O gramático Jerônimo Soares Barboza (1830, p. 201-203) mantém os modos verbais mencionados em Barros (1957 [1540], p. 29), embora de forma diferente. Como as correlações entre os modos listados por ambos os gramáticos já foram estabelecidas no início desta seção 4, nos deteremos apenas na relação entre subjuntivo e optativo, por ser essa central para a presente pesquisa. A diferente concepção dos modos subjuntivo e outativo é muito ilustrada na seguinte passagem de Barboza (1830, p. 203): "Quanto ao optativo, ja todos os Grammaticos, desenganados das antigas prevenções, lhe assignarão seu verdadeiro lugar no modo subjunctivo, de cujas linguagens se serve*.

Observamos que, nessa gramática do século XIX, diferentemente da anterior, do século XVI, os modos optativo e subjuntivo constituem um único grupo, o do modo subjuntivo. Mas a informação relevante em Barboza (1830, p. 204) está na consideração dos tempos verbais de duas maneiras: "ou como continuados e não acabados, ou como não continuados e acabados". Por exemplo, o tempo presente pode ser perfeito (sejas, tenha vindo) ou imperfeito (seja, haja de ser, esteja sendo).

Infelizmente, o gramático não avança na discussão desse valor aspectual dos tempos verbais. Ainda assim, essa aspectualidade pode ser importante para a análise da variação entre o presente do modo subjuntivo e o presente do modo indicativo, pois o indicativo tem se mostrado favorecido nos contextos em que a situação retratada na oração que contém o dado relevante se espalha em um eixo temporal que compreende passado, presente e futuro. Nesses casos, parece haver menos restrições: (i) o valor de futuridade não precisa aparecer isoladamente, pois aparece conjugado ao passado e presente, em um eixo temporal mais espraiado; (ii) o valor de futuridade não está marcado lexicalmente, como observado nos dados (1) e (2), pois, como o tempo é mais espraiado, a marca de futuro está presente na própria situação retratada no enunciado ou em outras marcas perceptíveis no discurso. 


\section{CONSIDERAÇÕES FINAIS}

A análise de materiais de séculos anteriores, valiosa fonte de pesquisa, reservou uma importante contribuição para o estudo da variação entre presente do modo subjuntivo e presente do modo indicativo. E, ainda que o levantamento feito em gramáticas históricas até o momento seja incipiente, duas considerações parecem ganhar relevo:

(i) a morfologia do presente do modo subjuntivo é mais preservada sob o escopo de verbos de desejo (querer, desejar), a mesma classe de verbos caracterizada por Barros (1957 [1540] como sendo do modo outativo e do tempo vindouro;

(ii) o valor aspectual previsto por Barboza (1830) pode contribuir para explicar o favorecimento do presente do modo indicativo em construções sintáticas em que o evento se espraia no eixo temporal, compreendendo passado, presente e futuro.

A relação estabelecida em (a), entre morfologia de presente do subjuntivo, tempo vindouro e modo outativo, traduz, mediante indiscutíveis evidências, a correlação, prevista por Givón $(1984 ; 1993 ; 1995 ; 2001)$, de uso do subjuntivo na modalidade irrealis, sub-modo deôntico, caracterizada pela fraca asserção e forte contestação, devido ao evento ser projetado para o futuro. Na medida em que esse modo verbal conjuga-se a outros termos do contexto linguístico, verifica-se um contexto harmônico (BYBEE et al., 1994), que tem, na história, fortes heranças.

Já o valor aspectual, apresentado em (b), pode fornecer evidências para a diminuição do presente do modo subjuntivo, considerando o enfraquecimento da modalidade deôntica, decorrente da diluição de um determinando evento entre passado, presente e futuro. Essa aspectualidade favoreceria, então, o aparecimento do presente do modo indicativo. Com outra terminologia, Givón (1984; 1993; 1995; 2001) e Bybee et al. (1994) falam de um continuum envolvendo as modalidades realis e irrealis, i.e., eventos situados no realis, na inteface realis-irrealis-no irrealis.

Todas essas considerações podem ser importantes para enriquecer o conjunto de traços apresentado logo no início do presente artigo:

[+ futuridade] [+ incerteza] [- duração] $=[+$ presente do modo subjuntivo]

[ \pm futuridade $][+$ incerteza $][+$ duração $]=[-$ presente do modo subjuntivo $]$

[- futuridade] [- incerteza] [- duração] $=$ [- presente do modo subjuntivo]

No conjunto de traços acima, o primeiro privilegia o uso do presente do subjuntivo; o segundo, com a diminuição do traço de futuridade pelo valor aspectual, parece constituir o contexto favorecedor à entrada do modo indicativo, modo verbal que seria mais empregado quando a ausência de futuridade se instala. 


\section{REFERÊNCIAS}

BARBOZA, J. Soares.. Grammatica philosophica da lingua portugueza. Lisboa: Tipographia da Académia Real das Sciencias, 1830.

BARROS, J. de. Gramática da língua portuguesa. Organizado por José Pedro Machado. 3ed, 1957 [1540].

BECHARA, E.. Moderna gramática portuguesa. São Paulo: Nacional, 1980.

BUENO, F. da S.. Gramática normativa da língua portuguesa. São Paulo: Saraiva, 1963.

BYBEE, J.; PERKINS, R.; PAGLIUCA, W.. The evolution of grammar: tense, aspect, and modality in the languages of the world. Chicago: The University of Chicago Press, 1994.

CARVALHO, H. M. de. A alternância indicativo/subjuntivo nas orações substantivas em função dos tempos verbais presente e imperfeito na língua falada do Cariri. Tese de Doutorado. Fortaleza: Universidade Federal do Ceará, 2007.

CEGALLA, D. P.. Novíssima gramática da língua portuguesa. São Paulo: Nacional, 1981.

CUNHA, C.. Gramática do português contemporâneo. Belo Horizonte: Bernardo Álvares S.A., 1978.

FAGUNDES, E. D.. As ocorrências do modo subjuntivo nas entrevistas do VARSUL no estado do Paraná e as possibilidades de variação com o modo indicativo. Tese de Doutorado. Universidade Federal do Paraná, 2007.

GIVÓN, T.. English grammar. Amsterdam/Philadelphia: John Benjamins, vols. I e II, 1993. 1995.

Functionalism and grammar. Amsterdam/Philadelphia: John Benjamins,

Syntax - a functional-typological introduction. Amsterdam/Philadelphia: John Benjamins, 1984.

2001.

Syntax: an introduction. Amsterdam/Philadelphia: John Benjamins, vols. I e II,

MEIRA, V.. O uso do modo subjuntivo em orações relativas e completivas no português afro-brasileiro. Dissertação de Mestrado. Universidade Federal da Bahia, 2006. 
MENDES DE ALMEIDA, N.. Gramática metódica da língua portuguesa. São Paulo: Saraiva, 1981.

NETA, A. A.. O uso de formas do indicativo por formas do subjuntivo no português brasileiro. Dissertação de Mestrado. Belo Horizonte: Universidade Federal de Minas Gerais, 2000.

PIMPÃO, T. S.. O escopo da negação e o modo subjuntivo. In: Estudos Linguísticos. Bauru, p. 719-724, 1999a.

Variação no presente do modo subjuntivo: uma abordagem discursivopragmática. Dissertação de Mestrado. Florianópolis: Universidade Federal de Santa Catarina, 1999b.

POPLACK, S.. A dinâmica sociolingüística da aparente convergência. DELTA, vol. 10, $\mathrm{n}^{\circ}$ Especial, p. 141-172, 1994.

The inherent variability of the French subjunctive. In: Current Issues in Linguistics Theory. 74, p. 235-263, 1992.

SAID ALI, M.. Gramática secundária e gramática histórica da língua portuguesa. Brasília: Universidade de Brasília, 1964.

SILVA-CORVALÁN, C.. The gradual loss of mood distinctions in Los Angeles Spanish. In: Language Variation and Change 6(3), p. 255-272, 1994. 